\title{
In Their Own Words: Pregnancy Prevention Needs of Latino Teen Mothers
}

\author{
Anne K. Driscoll ${ }^{1}$, Michael S. Brockman ${ }^{1}$, Peggy Gregory ${ }^{2}$, Denise Alvarado ${ }^{1}$, Melina M. \\ Bersamin $^{3}$, Marilyn Johns ${ }^{2}$, Faye Lee ${ }^{2}$, Darlene Liesch', Fe Moncloa ${ }^{2}$, Stephen T. Russell, \\ Carla Sousa $^{2}$ \\ ${ }^{1}$ University of California, Davis \\ ${ }^{2}$ University of California Cooperative Extension (UCCE) \\ ${ }^{3}$ Prevention Research Center
}

\begin{abstract}
Resumen
The high rate of teen births among Latino youth is a major topic of concern. While the national Latina teen birth rate is twice that of non-Latino whites, Latina adolescents in California are four times as likely to become parents as whites. Nonetheless, little research has focused on pregnancy prevention programs and effective evaluation of such efforts for Latina populations. In response to this absence of information, the National Council of $\mathrm{La}$ Raza (NCLR) offered a series of Latino teen pregnancy prevention strategies (Pérez \& Duany, 1992). This study explored parenting Latina teens' perspectives of the relevance of these strategies for pregnancy prevention programs in order to enhance our understanding of how to help Latino teen mothers delay a second birth, and to best provide programs and services that would enable them to improve life conditions for themselves and their children. Participants included 27 Latina teen mothers between the ages of 15 and 19 with one child. Teens from urban and non-urban settings and immigrant and U.S.-born teens were interviewed to allow for comparisons between these groups. The teens' responses were roughly consistent with the National Council of La Raza's (NCLR) recommendations. Few differences were found between U.S.-born and immigrant teens and between those living in urban and

La alta tasa de natalidad adolescente entre la juventud Latina es un asunto de gran preocupación. Aunque la tasa de natalidad nacional es dos veces mayor a la de blancos no-Latinos, Latinas adolescentes son cuatro veces más probables de convertirse en madres que las blancas. Sin embargo, se han hecho muy pocas investigaciones que se concentren en programas de prevención de embarazo y evaluación efectiva de dichos esfuerzos para la población Latina. En respuesta a esta ausencia de información, el Consejo Nacional de la Raza (CNLR) ofreció una serie de estrategias para la prevención de embarazos de adolescentes Latinas (Pérez \& Duany, 1992). Este estudio exploró la perspectiva de madres adolescentes Latinas acerca de la relevancia de las estrategias usadas en los programas de prevención de embarazo. De manera que sus opiniones aumentarían nuestro entendimiento de cómo ayudar a joven madres Latinas atrasar un segundo nacimiento, al igual que la mejor manera de proveer programas y servicios que permitirían que ellas mejoraran la calidad de vida de si mismas y la de sus hijos. Las participantes del estudio incluyeron 27 madres adolescentes Latinas entre las edades de 15 á 19 años de edad con un solo hijo. Adolescentes de zonas urbanas y no-urbanas al igual que inmigrantes y aquellas nacidas en los EU fueron entrevistadas para poder comparar entre estos grupos. Las respuestas de las jóvenes fueron más o menos consistentes con las del Consejo Nacional de la Raza (CNLR). Pocas diferencias fueron encontradas entre las jóvenes nacidas en los EU y las inmigrantes, y tampoco entre aquellas viviendo en comunidades urbanas y nourbanas.
\end{abstract} non-urban communities.

(C) 2003 Californian Journal of Health Promotion. All rights reserved.

Keywords: Latino, Teen Pregnancy, Prevention, Adolescent Parenthood 


\section{Introduction}

California's population is growing rapidly; due to immigration and high fertility rates, its Latino population is growing even faster. By 2025, Latinos will account for $44 \%$ of the state's people and $60 \%$ of the youth population (Clark, 2000; California Department of Finance, 1998). Thus, the needs and behavior of Latino youth will have significant impacts not only on their own futures but on the future of California as well. A major topic of concern is the high Latino teen birth rate which is higher than that of any other racial/ethnic group. While the national Latina teen birth rate is twice that of non-Latino whites, Latina adolescents in California are four times as likely to become parents as whites.

The Latino population faces challenges related to cultural differences and economic disadvantages. Its rapid growth will put pressure on educational and health care systems. Yet, due to limited research on the Latino population (Fennelly, 1993), we face the risk of having little information on which to base the design and implementation of appropriate programs and services for Latino youth. While the research community has explored the reasons for teen parenthood among white and African American youth for some time, only recently have researchers focused on Latino youth. Thus, relatively little is known about how to aid young Latinos to postpone parenthood, let alone assist young parents to prevent additional teen births.

\section{Background}

Young mothers are at higher risk for another birth than non-mothers; a second child is associated with a higher risk of a bleaker future for both mother and children. In 1999, onequarter of the births to Latina teens were to young mothers, that is, they were second or higher parity births (Curtin \& Martin, 2000). This statistic suggests that we need to know a great deal more about two topics - how to increase the odds that teen parents postpone a second birth until they are emotionally and financially ready for the additional responsibility, and how to help parents increase their chances for a good future for themselves and their children. Thus, interventions must be tailored not only for adolescents who are not parents but also for those who already have a child. It is important to help teens postpone childbearing until they reach adulthood. It is equally important to develop successful interventions to help young mothers avoid a repeat teen pregnancy.

Ethnographic research suggests that Latino culture endorses early and high fertility as well as the belief that motherhood and school are incompatible (Erickson, 1994). Latino girls desire marriage and children at a younger age than African Americans, Southeast Asians, and whites (East, 1998). Mexican Americans are more likely than whites to believe that marriage affirms one's womanhood (Oropesa, 1996). Also, although Latinos have more conservative attitudes towards sexuality than whites or African Americans (Ford \& Norris, 1993), they tend to enter sexual relationships earlier perhaps as a result of their desire to marry early.

These past studies indicate that cultural expectations unique to a particular ethnic group mold young women's expectations and values surrounding marriage and motherhood; these expectations, in turn, influence their sexual and contraceptive behavior. Studies of immigrant generation and acculturation also support the idea that cultural attitudes and beliefs influence sexual and contraceptive behavior. Most young Latinos face the challenge of coping with two cultures. This is particularly true of children of immigrant parents, including both immigrant and U.S.-born youth. Much research shows that more acculturated Latino youth behave differently than those less exposed to American influences, but past research has yielded somewhat mixed results on the effects of acculturation. U.S.-born girls hoped for younger parenthood than those born in Mexico; they also perceived a higher likelihood of having a nonmarital birth (East, 1998). Yet, while more acculturated Latinas are more sexually active, they are also more likely to use contraception (Ford \& Norris, 1993). Thus, it is not surprising that foreign-born pregnant adolescent Latinas 
are more likely to report that their pregnancy was intended (Frost \& Oslak, 1999) and are less likely to have an abortion than native teens (Aneshensel, Fielder \& Becerra, 1989). Immigrant pregnant teens are less likely to report being in abusive relationships and more likely to have strong support from the father than U.S.-born Latinas (Frost \& Oslak, 1999). Yet, Latino men with more traditional gender role beliefs are more sexually coercive towards their partners (Marin, Gomez, Tschann \& Gregorich, 1997).

Little research has focused on prevention programs and the evaluation of effective methods for educating Latina populations. The Program Archive on Sexuality Health and Adolescence (PASHA) illustrates the lack of programmatic efforts aimed or even tested on a Latino population. PASHA identifies programs that have a demonstrated effect on pregnancy and STD/HIV prevention (Card, Niego, Mallari \& Farrell, 1996). Of the thirty primary and secondary prevention programs selected, only eight were originally tested on populations with over $15 \%$ Latino participation. A review of two of these programs found that while the evaluations demonstrated success in contraceptive efficacy for the whole population, neither found effects for Latinos (Eisen \& Zellman, 1992). These results suggest that programs developed for white or African American youth are not suitable for Latinos.

Programs that have proven successful among primarily Latino populations illustrate that culturally relevant practices do exist; they can inform practitioners on how to best prevent pregnancies in their adolescent Latina clientele. Past work has identified a common set of issues, beliefs, and barriers facing Latino youth. For example, sexuality is often a taboo subject in Latino homes (Brindis, 1992). Studies have also noted a lack of parental communication regarding sexuality as well as little support for continued education in the face of motherhood (Brindis, 1992; Warrick, Christianson, Walruff \& Cook, 1993). One evaluation found that partner and/or parental disapproval resulted in Latina adolescents terminating contraceptive pill use (Erickson, 1994); another found that Latinas benefited from assertiveness training (Hovell et al., 1998). These findings suggest that programs addressing these issues may assist practitioners and educators in reducing Latina teen pregnancy. By better understanding the Latino population, an array of culturally relevant practices can be adopted by educators and practitioners who work with Latino youth.

To address the absence of information about effective pregnancy prevention programs for Latino youth, the National Council of La Raza (NCLR) gave specific attention to teenage pregnancy prevention strategies (Pérez \& Duany, 1992). The NCLR developed recommendations for effective Latino teenage pregnancy prevention programs that included:

1. having culturally-sensitive, non-judgmental staff,

2. being responsive to Latino sub-group differences,

3. emphasizing education and support high aspirations,

4. recognizing cultural values regarding gender roles,

5. involving the parents and families of teenagers,

6. conducting active outreach to involve young men (or teen fathers) in programs, and

7. including age-appropriate sexuality education.

This study explored parenting Latina teens' perspectives of the relevance of these recommendations for pregnancy prevention programs in order to enhance our understanding of how to help Latino teen mothers delay a second birth. A second goal was to learn how best to provide programs and services that would enable them to improve their and their children's lives. Specifically, we sought to identify strategies that Latino teen mothers view as supporting their roles as mothers and as preventing subsequent pregnancies so as to incorporate these perspectives into recommendations for effective pregnancy prevention programs among Latino populations in California. 


\section{Methods}

\section{Participants}

Twenty-seven Latina teens, ages 15-19, with one child were recruited through the professional and community networks of University of California Cooperative Extension (UCCE) Advisors based in counties in the Bay Area and Central Valley regions of California. Table 1 describes the sample. Using community networks, the Advisors recruited teens from collaborating agencies and pregnancy prevention programs. By including teens from both urban and rural locales, we hoped to gain a better understanding of how best to assist teen parents in both environments to effectively manage their lives and increase the odds of a bright future for themselves and their child. We expected that teens born in Mexico would differ from U.S.born Mexican Americans in important ways, including their attitudes on gender roles, family and parenthood. For this reason, the sample included both immigrant and U.S.-born teens.

Table 1

Description of Sample

\begin{tabular}{|c|r|r|}
\hline & Percent & N \\
\hline Immigrant Status & & \\
\hline U.S.-born & 63 & 17 \\
\hline Immigrant & 37 & 10 \\
\hline Location & & \\
\hline San Francisco Bay Area & 56 & 15 \\
\hline Central Valley & 44 & 12 \\
\hline Language of Interview & & \\
\hline Spanish & 26 & 7 \\
\hline English & 67 & 18 \\
\hline Both & 7 & 2 \\
\hline
\end{tabular}

\section{Design and Procedure}

Individual, face-to-face interviews were conducted with each respondent by members of the research team in either English or Spanish, depending on the respondent's language of choice. The interviews consisted of open-ended questions designed to elicit respondents' candid and detailed views of the best practices for teen pregnancy prevention. An interview guide was designed to probe individual perspectives as well as to uncover and inform unexpected issues and concerns the teen parents raised. The interviews were held at locations convenient for the respondents. All interviews were taped and transcribed. After transcription, Spanish interviews were translated into English. Translations were checked by at least one additional bilingual person to ensure their accuracy. The transcripts were analyzed using appropriate methods of analyzing qualitative data described in Strauss (1987). Members of the research team analyzed the data using QSR NUD-IST (Nonnumerical Unstructured Data Indexing Searching and Theory-building).

\section{Results}

The Latina teens' responses were roughly consistent with the National Council of $\mathrm{La}$ Raza's (NCLR) recommendations, however some differences were noted. These differences demonstrate the complexities involved in broadly delineating recommendations for effective, community-based pregnancy prevention programs.

\section{Staff should be culturally sensitive and non- judgmental.}

Teens were asked what program staff should be like. Overwhelmingly, responses included words such as "friendly," "helpful," and "someone you can talk to." Clearly, the teens wanted caring program staff who were 
genuinely interested in helping them. One teen shared her perspective of what staff should be like, stating, "Nice, polite, helping the teens, you know. Giving them advice. That's it." Others mentioned the importance of having program staff who understood their circumstances and had gone through similar experiences. One teen described her parenting class teacher, saying, "[S]he makes us feel so comfortable because she has a daughter herself, too, actually, and she lets us know about what she deals with...." Several teens were adamant about wanting nonjudgmental staff, one explaining, "You want supportive people who, that are not always wanting to put you down because you are a teenage mother."

The teens were asked if they believed that Mexican culture differed from other cultures. Younger girls saw no differences between Mexican culture and other cultures because all people "go through the same things" and share similar problems while a majority of the older teens believed that differences do exist. Teens who held that differences did exist pointed to factors such as religious beliefs and practices, holiday traditions, and gender roles. One U.S.born teen, replied, "Of course [Mexican culture is different from others] ... Different customs, different language, different religion, rituals.... There's a difference in every culture." Another U.S.-born teen used the issue of abortion as an example of cultural differences, stating, “... other cultures, they have the right to get an abortion. Mexicans, they [say] 'Oh, you can't have an abortion!' because they say it's bad. Or, 'How can you do that? It's like throwing [a baby] away or something." " Two U.S.-born teens, referring to their bicultural heritage, cited gender role differences within their own families to illustrate differences between Mexican culture and others. One explained, "... guys have to get served before girls, then girls eat, and it's just, you know, you clean the house, you do this, you do that. And so my mom's side of the family, it's totally opposite, you know." The other shared, "My mom's side of the family, like the women are supposed to do all the cooking and the cleaning ... and all this. But on my father's side, like most of them are, they go to college, they have good jobs, they don't stay home and take care of the kids."

Teens were then asked whether it mattered if the program staff were able to speak Spanish and if they were Mexican. To the majority of these teen mothers, the ability of staff to communicate in Spanish was very important but being Mexican was not. However, most teens felt it was important for program staff to understand Mexican culture. Some suggested that greater cultural understanding would allow staff to help clientele more effectively; others implied that such understanding is important because program staff may work primarily with Mexican populations. One teen summarized these views well, stating, "[H]ow are you going to help someone ... if you really don't understand what, you know, what their background is? ... [Y]ou don't have to be a nationality to understand it ... but I think everyone should have a broad understanding of different cultures."

Interviewers asked the teens if it mattered if the staff had been (or were) teen parents themselves. Two-thirds responded that this was important. As one noted, "[T] hey would understand more if they were [teen parents], if they had been there before," succinctly capturing a common theme.

Interviewers then asked if staff age was an important factor. A small number of the teens said that the age of program staff mattered. However, their reasons referred primarily to staffs' ability to demonstrate understanding rather than to their chronological age. Two teens suggested that older staff would be valuable due to their greater experience and knowledge, but also mentioned that younger staff might be more understanding and easier to get along with. Addressing this issue of understanding, one teen shared,

"I think not that they should be your same age, but close, because different generations grew up with different thinking.... There's ... some people [who] are just so headstrong ... that's how it's been since they were growing up, so it's hard for them to understand, it's hard for them to learn about how it is now." 
Teens who responded that age did not matter spoke of the importance of having staff who can draw on personal experience. As stated by one teen-

"[W]hen you hear somebody that's just all research and tries to talk to you about teen parents and [has] never been through it ... they're not really going to follow her as in somebody that's older and that was a teen parent and struggled as much as you did at that age, then you would understand her better than somebody that didn't."

Finally, interviewers asked the teens whether it mattered if the staff were single or had never had children. Most teens said that having single program staff did not matter. Somewhat fewer than half of the teens thought that staff should have children of their own. Those who responded affirmatively implied that parenthood would give staff a greater understanding of "what they were going through." One respondent who shared that parenthood did not matter qualified her response, stating, "No, it doesn't matter if they have or they haven't, but that they really know what it's like having a baby ... what you lose when you have a baby."

Although the teens did not use the words "culturally sensitive and non-judgmental" to describe model program staff, their responses strongly paralleled these themes. The majority of the teens seemed to suggest that program staff ideally understand Mexican culture, speak Spanish, and have experienced teen parenthood.

\section{Staff should be sensitive and responsive to Latino sub-group differences.}

Interviewers shared the recommendation that staff should be sensitive and responsive to Latino sub-group differences and asked if their own background and place of birth mattered. Only two teens responded affirmatively, one explaining, "Yes. Because certain parts have ... different rituals, they just grow up their kids differently. It's like America, you know, the western part is different than the eastern part. So, why wouldn't it be the same in any other country?" The other teen, sharing her experience of inequitable treatment, said, "Well, it's important ... because maybe if I was born here I wouldn't have so much discrimination about so many things." The majority of teen mothers felt that sub-group differences are not important issues for program staff. Speaking on the issue of judging others based on their country of origin, one teen stated, "No, it doesn't matter as long as we get along pretty well. Then, it doesn't matter to me where other people come from or where I come from, as long as you don't keep judging other people...."

All agreed that staff origin and place of birth did not matter. One teen pointed to the importance of having culturally proficient staff, astutely summing up the view of a majority of her peers: "I don't really think [it matters] if they were born in the U.S. [or not], but as long as they have an understanding of all the diversity that we have here - the many cultures and stuff." For the most part, teens voiced concerns of being judged based on their country of origin, rather than maintaining that cultural differences be noted and appreciated by program staff. Instead of emphasizing recognition of sub-group cultural differences, the teens stressed the importance of equitable treatment for all individuals.

Programs should promote education and support high aspirations.

All of the teens said that programs should encourage them to get an education. These teen mothers understand that education is an important way to improve their lives and the lives of their children. The most common theme was the belief that education is the route to economic security: "They should encourage college, to go to college, okay. So you can get the good jobs." Another teen was adamant that education was very important to her:

... when you're out there in the world and you're by yourself on your own, you need an education to get somewhere, to get the things that you want because there's nothing wrong with welfare, but if you're on that, you're not going to have things, you're not going to have stuff that you want, your baby's not 
going to have. If you work, you know, if you have your diploma, you're going to find a better job and you're able to get things you want.

A second theme was that education leads to general self-improvement. Others mentioned reasons such as improving life for their baby or learning necessary information. One teen said,

"It's always good to finish school... [W] hat's going to happen when you're kids want you to help them with their homework and you don't know because you never finished it. It's about being helpful with your kids and ... to help them have a good education...."

The respondents agreed that programs should provide support for them to finish high school and continue on to college because "They should encourage us because we need the support.". One said, "Because, because you need your education and sometimes if you don't get it from the family to have the support, you know, to get the programs to do it." Another said, "Because, the fact of them giving the support would be like, they're like, not making us, but helping us get ... an education, and just, of them caring."

The respondents were then asked if prevention programs should assist teen parents in preparing for the world of work. Only two disagreed with this idea. Fewer than half of the teens had ever worked, so the concept of working was more related to the future. Several thought opinion that while work is important, education was a necessary prerequisite. Others viewed work as an economic necessity. One teen said, "Well, yes, because of the fact that you can't take care of your child on welfare for the rest of your [life] because now all the laws have changed, so it's not like everything's for free now. And you know you've got to work to provide, just like everybody else does." Suggestions for workrelated activities included job training and skills such as how to fill out applications. In sum, while most teens felt it was important for programs to encourage employment, getting an education first was more important to them.
Teens were also more focused on future than current employment.

\section{Programs should recognize cultural values regarding the role of mothers and fathers as parents.}

Overall, one-third endorsed an equal division of responsibility between mothers and fathers. One teen mother said,

Yes I think so, because sometimes I think that the man thinks that just because they work, no I already worked, so then you take care of the baby ... in the middle of the night, whatever, and I think that it's not like that because if, if that person helped you make him I think that he has the responsibility to take care of him too.

Three teen mothers suggested classes for fathers:

“... when he's very tired he tells me, no let me sleep because I'm going to go in very early. But I say ... it's your problem to take care of him, he's crying, and I think that there should be classes for them to understand that, that it wasn't just one person, it was two persons."

A number of teens felt that decisions about division of responsibility were personal and that programs should not get involved. One teen said, "No, because they, it's like somebody telling you what to do. It's like another mother or father. And to me, I mean, I'm old enough to take care of myself." Another said, "... you can decide that on your own, who wants to work and who wants to stay home and take care of the baby."

\section{Programs should involve the parents or families of teen parents.}

The majority of the teens thought that programs should involve their parents most commonly because such involvement would help parents be more understanding of the teens' situations. One teen said,

"Oh, I think it should. Because you get to know the grandparents of the kid and the parents should get to know like what the 
kids are doing, because sometimes they don't even know what the kids are doing, and like where they're going. That's why the parents should know where they are, like the community, where they're going, how their school is going, everything."

Another reason given for parent involvement was that it would improve the teen's relationship with her parents. One teen said, "Yeah, that would be okay. If parents are not okay with their children or, or they're not okay with their children having other children ... or they need counseling, ... the parents should be involved." Another explained, "Because maybe the parents don't always understand how hard it is, especially if they didn't have us when they were teens. It's much different. If they're more aware of like how you feel, and stuff like that, better relationship."

The most common reasons given for disagreeing with involving the parents of teen parents was that caring for the baby is the teen's responsibility and that the parents are busy working and probably would not participate. One teen said, "I don't think so. Cause they have things to do, they work two jobs, how are they going to go to the program or something, you know?" She continued, "So I don't think the parents really should be involved unless the parents want to."

About half of the teens agreed with involving other family members. Several stated that it would help younger family members to avoid the same mistake. One teen mother said, "[They could be involved] by just seeing what happened to you and not doing the same thing as your sister did, don't fall for the same thing." Another said,

"Yeah, I'm trying to educate my brother right now, what the consequences are and what not to do, and he's real good. $\mathrm{He}$ doesn't do drugs, he, he's already going to be a sophomore, and he doesn't really have girlfriends, he's just dating and he's doing better than I did when I got pregnant when I was freshman, so he's doing way better, I mean."
The teens who felt otherwise did not view their situations as their families' concern, but rather their own problem.

\section{Programs should try to include the baby's father.}

Almost all of the teen mothers endorsed the recommendation that programs involve the fathers of their babies. The teens clearly thought that the father's involvement with the baby is important and that programs should find effective ways to include them. They said that fathers need information in order to learn to take responsibility and to think about the future. Some recommended separate classes for the fathers. One teen mother said, "They need to talk to them and see what his side [is]."

\section{Programs should offer age-appropriate sexuality education.}

Most teens adamantly maintained that pregnancy prevention programs should include sexuality education. One teen referred to the issue of preventing subsequent pregnancies:

"Well, I think so, primarily for that so you don't commit the same mistake. I know girls that, that have a child at 17 , at 19 they have another one, at 20 they have another one, and they go on like that, on and on. ... So then it would be good if someone would also talk about those things, because that way we would know more about what can happen, how we can take care of ourselves not to, well not to [have more children]."

Another teen, addressing both sexually transmitted infection (STI) and pregnancy prevention, shared, "Because if they give us sex education, we'll know ... all the different kinds of [sexually transmitted infections] and what we can do to prevent getting them. And we'll know ... some girls don't think you can get pregnant with, after doing it one time, but that happens." Also pointing to the consequences of risky sexual behavior, one teen affirmed, "Yes, they should talk about that, because there are a lot of people that have sex just like that and ... they don't even know the consequences and what can happen." Highlighting the need for sexuality education to begin in the earlier grades, one teen 
stated, "... they need to talk to ... the whole range of kids, from $4^{\text {th }}$ and $5^{\text {th }}$, that would be okay." Clearly, these teens believed in the importance of sexuality education and its value as a key component of pregnancy prevention programming.

When asked what topics sexuality education should cover, most mentioned STIs and birth control. Only two teens specifically referred to the danger of HIV/AIDS, drawing attention to the need for further education in this area. One of the two, went on to cite a host of other important issues-

"Protection from STDs, from AIDS. ... Let them know that their sexuality is very important, that they don't need to do it just because everyone else is doing it. ... [S]ometimes kids are under the impression that, you know, all they have to do is use a condom when they're having sex and they won't get an STD, when there are so many other ways they can, you know."

Another teen referred to the barriers to teaching sexuality education in public schools, stating,

"Everybody wants to know about abstinence, and yeah, I mean, I think it's a good thing. But in reality ... abstinence isn't taking place right now. And the more you tell, especially teenagers, not to do something, they're exactly going to do it. I think they ought to know the fact that, you know, what kind of diseases are out there as in STDs and stuff like that because those do take place when you're, when you're in that kind of situation, having sex. ... It's not that trying to tell your teenagers that it's okay, because it's not. But I would give them that response as you could do other things ... as in birth control, just anything like that, because some people could make that mistake and then try not to, or don't do it until years later. ... I mean they say that there's teen pregnancy, but they don't, you can't talk about any kind of birth control here or ... condoms or anything like that."
Speaking about the importance of sexuality education for males as well as females, one teen declared, “... [M]any men don't want to protect themselves. They just want the women to protect themselves. I think that they should ... tell us that both of us have to.... They have to explain to the men who don't know how to protect themselves...."

\section{Discussion}

The teen mothers we interviewed discussed many of the challenges of adolescent parenthood such as staying in school, getting advanced education, child care, and relationships with the baby's father and grandparents. We found that, overall, these Latina teen mothers agreed with NCLR's recommendations for effective Latina teen pregnancy prevention programs. Further, we found few differences in opinion between the Bay Area and Central Valley teen mothers, and only small differences between Mexican-born and U.S.-born teens. We highlight these issues below, pointing out the areas in which these young mothers differed in opinion from the "best practices" offered by NCLR.

Overall, teens suggested that while staff need to understand Latino cultures, it is more important that they be able to relate to program participants personally and understand the challenges of teenage parenthood. The staff's ability to empathize with the girls' life circumstances appeared to be more important than the ability to speak Spanish, being of Mexican background, being a parent, or being young.

All of the teens agreed that education and economic self-sufficiency are important for life success for themselves and for their children. The young women agreed with the commonly held U.S. belief that advanced education permits independence from a partner or from family. Most of the young women had adopted the typical U.S. expectation that men should be involved with child rearing and many wanted social programs to assist their babies' fathers to be more involved in their children's lives.

Involving families in program activities was strongly supported by most teens in this study. 
Most emphasized the importance of involving their parents expecting that it would improve their own relationship with their parents by helping their parents better understand the challenges they face as teen mothers. Because Latino cultures highly value family bonds and relationships, involving parents and extended family will likely enhance the programs' legitimacy and influence in the lives of the teen mothers and be more likely to produce the desired outcomes.

The teenagers we interviewed appeared to be moving from their traditional family-centered culture to the more individualistic U.S. culture in which they live. Adults working with teens must not only be sensitive to Latino cultures but also understand the acculturation process and the particular challenges of adjustment teenagers face.

For many of the teens in this study, the challenges of parenthood are compounded by their attempts to bridge two cultures. Olsen (1997) suggests issues of sexuality, dating, gender roles, and freedom and independence from parents are particularly difficult for new immigrant teenaged girls. Those who are pregnant or parenting confront these and many other issues which teen pregnancy prevention and parenting programs aim to address. However, although we expected to find meaningful differences between the opinions of U.S.-born and immigrant teen mothers, for the most part, we did not. It is possible that, on the topics covered, there are few differences in the views or needs of immigrant and native young mothers. It is also possible that the immigrant and U.S.-born teens in this study resembled each other more closely than is true in general as they were recruited from similar programs. They may represent a sample of young mothers who subscribe to similar views about the role and purpose of such programs, whereas a wider sample that also included teens not enrolled in formal programs might generate a wider variety of responses.

We had anticipated that the opinions expressed by young Latina mothers living in the Bay Area would differ from those living in the southern Central Valley. Instead, we found their perspectives on pregnancy prevention program efforts to be remarkably consistent. At the local level, it is often assumed that effective practices in urban areas are irrelevant for non-urban settings, and vice versa. In the case of programs to support pregnancy prevention among pregnant and parenting Latina teens, there is little evidence from the teens themselves that significantly different programmatic approaches are warranted. While all prevention programs must respond to the local setting and context, our study suggests that we all may have much to learn from existing effective programmatic efforts - regardless of the community setting.

Although teen mothers were asked about including their child's father and their families in pregnancy prevention programs, we gathered no first-hand information from either group about their needs or roles and the best way to involve them. Future research could address the needs and issues of young Latino fathers and explore how best to assist them in being good fathers to their children. Likewise, interviewing the parents and siblings of Latina teen mothers would also provide insights into how parents can best support their children and the risk of teen pregnancy among younger siblings can be lowered.

\section{References}

Aneshensel, C. S., Fielder, E. P., and Becerra, R. M. (1989). Fertility and fertility-related behavior among Mexican-American and non-Hispanic white female adolescents. Journal of Health and Social Behavior, 30(1), 56.

Brindis, C. (1992). Adolescent pregnancy prevention for Hispanic youth: the role of schools, families, and communities. Journal of School Health, 62(7), 345-51.

California Department of Finance. (1998). Sacramento, CA. Retrieved from http://www.dof.ca.gov/html/fs_data/stat-abs/sa home.htm 
Card, J. J., Niego, S., Mallari, A., and Farrell, W. S. (1996). The program archive on sexuality, health \& adolescence: Promising "prevention programs in a box". Family Planning Perspectives, 28, 210 220.

Clark, W. A. V. (2000). Immigration, high fertility fuel state's population growth. California Agriculture 2000, 54(1), 19-25.

Curtin, S. C., and Martin, J. A. (2000). Births: Preliminary data for 1999. National Vital Statistics Report, 48(14), 1-20.

East, P. L. (1998). Racial and ethnic differences in girls' sexual, marital, and birth expectations. Journal of Marriage and the Family, 60(1), 150.

Eisen, M., and Zellman, G. L. (1992). A health beliefs field experiment: Teen talk. In B. Miller et al. (Eds.), Preventing adolescent pregnancy: Model programs and evaluations. Newbury Park, CA: Sage Publications.

Erickson, P. I. (1994). Lessons from a repeat pregnancy prevention program for Hispanic teenage mothers in east Los Angeles. Family Planning Perspectives, 26(4), 174-8.

Fennelly, K. (1993). Sexual activity and childbearing among Hispanic adolescents in the United States. In R. Lerner (Ed.), Early adolescence: Perspectives on research, policy and intervention. Hillsdale, NJ: Lawrence Erlbaum \& Associates.

Ford, K., \& Norris, A. E. (1993). Urban Hispanic adolescents and young adults: Relationship of acculturation to sexual behavior. The Journal of Sex Research, 30(4), 316.

Frost, J. J., \& Oslak, S. (1999). Teenagers' pregnancy intentions and decisions: A study of young women in California choosing to give birth. Occasional Report. No. 2. New York: The Alan Guttmacher Institute.

Hovell, M., Blumberg, E., Sipan, C., Hofstetter, C. R., Burkham, S., Atkins, C., \& Felice, M. (1998). Skills training for pregnancy and AIDS prevention in Anglo and Latino youth. Journal of Adolescent Health, 23(3), 139-49.

Marin, B. V., Gomez, C. A., Tschann, J. M., \& Gregorich, S. E. (1997). Condom use in unmarried Latino men: A test of cultural constructs. Health Psychology, 16(5), 458-67.

Olsen, L.(1997). Made in America: Immigrant students in our public schools. New York: New Press.

Oropesa, R. S. (1996). Normative beliefs about marriage and cohabitation: A comparison of non-Latino whites, Mexican Americans, and Puerto Ricans. Journal of Marriage and the Family, 58(1), 49.

Perez, S. M., \& Duany, L. A. (1992). Reducing Hispanic teenage pregnancy and family poverty: A replication guide. Washington, DC: National Council of La Raza.

Strauss, A. L. (1987). Qualitative analysis for social scientists. Cambridge: Cambridge University Press.

Warrick, L., Christianson, J. B., Walruff, J., \& Cook, P. C. (1993). Educational outcomes in teenage pregnancy and parenting programs: results from a demonstration. Family Planning Perspectives, $25(4), 148-55$.

\section{Acknowledgements}

This article is a product of the Latino Teen Pregnancy Prevention Workgroup of the Division of Agriculture and Natural Resources (ANR) of the University of California.

This research was made possible in part by funding from a UC MEXUS small grant (Principal Investigator Stephen T. Russell, Ph.D.), a UC MEXUS grant (Principal Investigator Anne K. Driscoll, Dr.P.H.), as well as through University of California Agriculture and Natural Resources (ANR) workgroup funding.

We would like to thank all those who volunteered to participate in this study. We also thank Karen McCluskey, Denise Alvarado, and Ashley Waddington for their contributions to the research team. 
$\underline{\text { Author Information }}$

Anne K. Driscoll*

Michael S. Brockman

Denise Alvarado

Stephen T. Russell

Department of Human and Community Development

University of California, Davis

E-Mail: akdriscoll@ucdavis.edu

Peggy Gregory

Marilyn Johns

Faye Lee

Darlene Liesch

Fe Moncloa

Carla Sousa

University of California Cooperative Extension (UCCE)

Melina M. Bersamin

Prevention Research Center

* Corresponding author 